\title{
Why did the term structure of interest rates lose its predictive power?
}

\author{
Caroline JARDET* \\ CREST and EUREQua
}

March 15, 2002

\footnotetext{
${ }^{*}$ Caroline JARDET - CREST laboratoire de Macroéconomie - Timbre J360 - 15 boulevard Gabriel Péri - 92245 Malakoff cedex - France, 33-1-41-17-60-38, Fax 33-1-41-17-76-66, jardet@ensae.fr.
} 


\title{
Why did the term structure of interest rates lose its predictive power?
}

\begin{abstract}
In this paper, we perform a multiple structural change test that makes it possible to detect a break in the correlation between spread of interest rate and future activity in 1984 for US monthly data. Basic regressions show that this break is associated with the loss of the predictive power of the term structure. Hence, in order to identify causes of this change, we estimate a structural VAR-VECM model of the joint dynamics of macroeconomic fundamentals and term structure of interest rates. It is then possible to compute the contributions of each structural shocks in generating the predictive power of the spread of interest rates. The results reported indicate that the loss of predictability of the spread is due to a substantial drop in both contributions of monetary policy and supply shocks.

Keywords: yield curve, term structure, monetary policy, structural changes. JEL Classification : E43, E52, C22.

\section{Résumé}

Dans la première partie de ce travail, on teste la stabilité du coefficient de corrélation entre le taux de croissance du produit et la pente de la courbe des taux aux États-Unis. L'hypothèse de stabilité est rejetée, et une rupture est détectée au premier trimestre 1984. Celle-ci est associée a une perte du pouvoir prévisionnel du spread de taux d'intérêt. La seconde partie de l'exercice consiste à identifier les causes de cette rupture. Un modèle VARVECM structurel est estimé. On peut alors quantifier la capacité de chaque choc structurel à engendrer le pouvoir prévisionnel du spread de taux. On montre alors que l'affaiblissement de cette propriété semble être dû à une baisse du rôle joué par les chocs d'offre et de politique monétaire.

Mots clés : courbe des taux, politique monétaire, changement de structure. Codes JEL : E43, E52, C22.
\end{abstract}




\section{Introduction}

The Leading Indicator Property of the Term Structure (thereafter LIPTS) has motivated a lot of empirical studies. All of them (Stock and Watson (1990), Harvey (1989), Chen (1991), Estrella and Hardouvelis (1991), Hu (1993), Plosser and Rouwenhurst (1994), Estrella and Mishkin (1997)) have emphasized the existence of a strong correlation between future activity and the spread of interest rate, defined as the difference between long term and short term rates.

The Figure 1 displays the slope of the yield curve, computed as the difference between the yield of ten year treasury bond and federal fund rate, and the growth rate of the gross domestic product (thereafter GDP) since 1970. At the beginning of the period the slope of the yield curve appears to be a leading indicator of GDP growth, with a regular lag of about one year. However this relationship seems to disappear at the end of the period. Thus, the historical relation between spread and activity seems to have vanished in the early 1980 s.

The paper has two objectives. The first is to present a proper statistical test of break in the empirical relationship between the growth rate of GDP and the slope of the yield curve. For this purpose, we test the stability of the correlation coefficient between the spread and future activity. The approach is based on Bai and Perron's methodology (1998), and leads to a rejection of the stability hypothesis. In addition we can date the break in the first quarter of 1984.

Our second objective is to identify the causes of this structural change. Although the LIPTS is empirically well documented, few studies have tried to justify it theoretically.

A first explanation hinges on the CCAPM model (Harvey (1988), Hu (1993)) which has difficulties to account for some of the empirical evidences. According to this theory, the LIPTS principally results from agents' smoothing behavior of their consumption profile. when a recession is expected, agents

buy today long term risk-free assets to insure themselves against an future 
reduction of their income. Long term yields decrease and the yield curve flattens. So a recession is well predated by a decline in the interest rates spread.

A second strand of the literature assigns to the behavior of the monetary authority the LIPTS. The central bank can control the short term interest rate via its interventions on the money market. In this case, the short term interest rate is best viewed as an intermediary tool of monetary policy. Activity and prices respond to the long term interest rate. According to the expectation theory of the term structure, the long rate is equal to a weighted average of expected short term interest rate plus a term premium that is rather stable. Therefore, the control of the short term interest rate makes it possible to influence the long rate and future activity. For instance, an expansionist monetary policy, i.e a drop in the short term interest rate, leads to a decline in the long term rate that, in turn, boosts activity. In this case, the increase in the spread induced by the falling short term interest rate, predates the recovery.

According to Bernanke and Blinder (1992), LIPTS is principally generated by monetary policy. Estrella and Hardouvelis (1991) and Plosser and Rouwenhurst (1994), show that actions of monetary authority contributes to LIPTS, but cannot by themselves explain all the observed correlation between the spread and real activity.

In the second part of this paper we seek to identify factors responsible for the loss of the predictive power of the yield curve in 1984. More particularly we study whether the reduced impact of monetary policy identified in the early 1980s can explain the disappearance in the LIPTS. To answer this question we estimate a structural VAR-VECM model. We identify four structural shocks : a supply shock, a demand shock, a short term interest rate shock (or monetary policy shock) and a long term interest rate shock. Then we measure the contribution of each structural disturbance to the correlation between the spread and future activity. This decomposition is an improvement on the existing literature. We find a drop in the joint contributions of supply and monetary policy shocks after the 1984 break. 
The paper is organized as follows. Section 2 details the results of the stability test that detects the breakpoint. Section 3 describes the structural VAR-VECM representation used to identify the structural disturbances. It presents the contributions of the four structurals shocks to the predictive of the term structure. Section 4 concludes.

\section{The changing predictive power of the term structure}

In this section we focus on linear regressions in which the dependent variable is growth in real GDP. The explanatory variable is a measure of the slope of the yield curve lagged six months to two years. We look for a change in the empirical relationship between these two variables.

\subsection{An empirical evidence : basic regressions}

Consider the annual "marginal" ${ }^{1}$ growth rate of real monthly GDP :

$$
\Delta y_{t}=y_{t}-y_{t-12}
$$

where $y_{t}$ is the logarithm of the level of real monthly GDP at time $t$.

We note $\left(R_{t}-i_{t}\right)$ the slope of the nominal yield curve, that is to say the difference between the long term bond yield $R_{t}$ and the short term interest rate $i_{t}$ at time $t$.

The following basic regression is a way to describe the positive correlation between spread and future activity :

$$
\Delta y_{t}=\alpha+\beta\left(R_{t-k}-i_{t-k}\right)+\eta_{t}
$$

where $k$ is the forecast horizon and $\eta_{t}$ is the forecast error. The fact that we work in months and that $\Delta y_{t}=y_{t}-y_{t-12}$ creates some temporal correlation between the successive error terms. Hence, $\eta_{t}$ may be assumed to have

\footnotetext{
${ }^{1}$ We also find in the litterature the "cumulative" growth rate measure as, for a given horizon $k: \Delta^{k} y_{t}=y_{t}-y_{t-k}$
} 
a moving average representation. Then, the serial dependence in the error term is accounted for in the estimation of the covariance matrix using the Newey and West (1987) estimator.

We estimate equation 2 using US monthly data from 1957-01 to $1998-12^{2}$ for an horizon from 0 to 30 months. The results are reported in Table 1.

(insert here Table 1)

The slope coefficient is strongly significant for horizons between six and eighteen months. In addition, according to the $R^{2}$ criteria, the largest predictive power is at the one year forecast horizon, where thirty percent of the variation in the annual growth rate of GDP is explained by the slope of the yield curve.

\subsection{Structural stability tests}

In this sub-section we test the stability of the coefficient $\beta$ in equation (2). At this stage of the analysis, from Figure 1 we do not know if there are zero, one or several breakpoints. For this reason we perform a multiple structural changes test as presented in Bai and Perron (1998).

Bai and Perron propose a sequential procedure that allows to test the null hypothesis of, say, $l$ changes, against the alternative hypothesis of $l+1$ changes. The dates of the breaks are treated as unknown and are estimated by minimizing the sum of squared residuals ${ }^{3}$. The results of the test are presented in Table 4.

\section{(insert here Table 4)}

As judged from Table 4, we reject the hypothesis of no break against one break for each forecast horizon between six months and two years. The date of the break is estimated to be the first quarter of 1984 .

\footnotetext{
${ }^{2}$ See appendix for a complete description of these data.

${ }^{3}$ See appendix for details on this test and asymptotic critical values.
} 
Furthermore for each forecast horizon, the test never rejects the hypothesis of a single break against two breaks.

Thus, we conclude to the existence of a single break in 1984 .

This period coincides with important modifications of the monetary policy regime in the United-States. These changes began with the nomination of Paul Volcker as Fed chairman in september 1979, but the most fundamentals modifications occurred in 1982 and after. By 1984, the break can be connected with the move to a monetary policy regime more concerned with inflation.

The end of 1983 also marks the beginning of a set of measures that have profoundly modified financial markets. In 1983, the SEC (Security Exchange Commission ) has encouraged securitization. Casual reasoning suggests that if monetary policy operates through the credit markets, and if securitization has transformed the credit markets, this may have had important effects on the transmission mechanism. Securitization is likely to be a weakening of the impact of monetary policy (Estrella (2001)).

\subsection{Basic regressions before and after the break}

We divide the whole sample in two sub-samples. The first one contains all the observations from 1957-01 to 1983-12. The second sub-sample covers the period from 1985-01 to 1998-12. For each forecast horizon, (2) is stable on both sub-samples.

We estimate this equation before and after the break. The results are reported in Table 2 for the first sub-sample, and in Table 3 for the second sub-sample.

(insert here Tables 2 and 3) 
Before the break, the interest rate spread of interest rate is a good leading indicator of real activity. For all the forecast horizons between six months and two years, the coefficient $\beta$ in (2) is strongly significant. The best prediction is obtained with the one year forecast horizon. Then, the $R^{2}$ is about $50 \%$.

The results differ significantly when estimations are performed on the second sub-sample. For almost all the forecast horizons, the coefficient $\beta$ is not significant anymore. In addition, the low value of the $R^{2}$, which is never higher than $14 \%$, indicates the poor quality of (2) in predicting future activity.

So the 1984 change is associated with the loss of predictive power of the term structure. The following sections try to identify the causes of this change.

\section{A predictive power decomposition in a VAR framework}

In this section, we investigate why the slope of the yield curve is not as good predictor as before 1984. More precisely, we try to answer to following question: Can the declining role of monetary policy disturbance on activity recorded in the early 1980s explain the loss of predictive power of the term structure? For this purpose, we estimate a structural VAR-VECM representation on both sub-samples using restrictions that allow to identify monetary policy shocks ${ }^{4}$. The structural model allow to calculate indicators that quantify the contribution of each structural disturbance to the LIPTS.

\footnotetext{
${ }^{4}$ That is, exogenous changes in short term interest rate.
} 


\subsection{The empirical specification of the VAR-VECM}

Let $X_{t}$ be a $(n \times 1)$ vector, integrated of order 1 and cointegrated of order $(1,1)$. So, there exists a $(r \times n)$ matrix, noted $\alpha$, of rank $r$ with $r \leq n$, such that $\alpha^{\prime} X_{t}$ is stationary. The $X_{t}$ vector admits the following Wold representation :

$$
(1-L) X_{t}=\delta+C(L) U_{t}
$$

where $L$ denotes the lag operator, $C(z)$ is a $(n \times n)$ matrix of lag polynomials such that $C(z)=I_{n}+\sum_{i=1}^{\infty} C_{i} z^{i}$ is finite for all $z$ inside the unit circle. $I_{n}$ is the $(n \times n)$ identity matrix, $\delta$ denotes the mean of $(1-L) X_{t}$. $U_{t}$, the statistical innovations vector, is a random vector of size $(n \times 1)$ such that $E\left(U_{t}\right)=0, E\left(U_{t} U_{t}^{\prime}\right)=\Sigma$ and $E\left(U_{t} U_{t-k}^{\prime}\right)=0$ for $k \neq t$.

Engle and Granger (1987) have shown that the $X_{t}$ process defined in (3) admits a VECM representation of the form :

$$
A^{*}(L)(1-L) X_{t}=\rho-\gamma \alpha^{\prime} X_{t-1}+U_{t}
$$

where $\gamma$ is a $(n \times r)$ matrix of rank $r$ and $A^{*}(L)$ a $(n \times n)$ matrix of lag polynomials.

Now, we consider the vector :

$$
X_{t}=\left(\begin{array}{c}
y_{t} \\
p_{t} \\
i_{t} \\
R_{t}-i_{t}
\end{array}\right)
$$

where $y_{t}$ is the detrended logarithm of the real $\mathrm{GDP}^{5}, p_{t}$ denotes the logarithm of prices, $i_{t}$ is the federal fund rate and $R_{t}$ the ten years government bonds yield.

The model (4) is estimated on both sub-samples. Note that the second subsample is chosen so that the lagged variables are dated posterior to the date of the break.

\footnotetext{
${ }^{5}$ See the appendix for details.
} 
The AIC information criterion leads us to consider 5 lags for the VAR representation estimated on the first sub-sample, and 7 lags for the second sub-sample.

(insert here Tables 5 and 8 )

The trace and $\lambda_{\max }$ statistics, proposed by Johansen and Juselius (1990), lead us to select 2 cointegrating relations in both sub-sample. In each case we cannot reject the hypothesis that the matrix

$$
\alpha=\left(\begin{array}{cc}
0 & 0.4 \\
0 & 0 \\
0 & 1 \\
1 & 1
\end{array}\right)
$$

pertains to the cointegrating space. The first cointegrating relation indicates the stationarity of the spread. According to the second cointegrating relation, there exists a long term relationship between output and the long term interest rate.

\subsection{Identification of structural shocks}

Our empirical representation leads us to identify four structural shocks. The two first structural disturbances are shocks to macro-fundamentals, identified as usual in the literature, as the basic impulses driving the joint dynamics of the macro variable and of the term structure. More precisely, we consider a "supply" shock, denote $\varepsilon^{s}$, and a transitory "demand" shock, $\varepsilon^{d}$.

The two remaining shocks are shocks to the "short term" and "long term" nominal interest rates respectively. Following Gali (1992), we assume that these shocks affect the output with a lag. The "short term" nominal interest rate shock is also called "monetary policy" shock, denoted $\varepsilon^{p}$. In other words, consistently with many VAR studies, we interpret monetary policy as exogenous changes in the short term nominal interest rate (here, the Federal Fund Rate $)^{6}$. The "long term" nominal interest rate shocks, $\varepsilon^{l r}$, includes all

\footnotetext{
${ }^{6}$ See Goodfriend (1993) for a discussion of premises underlying this interpretation of policy.
} 
the disturbances affecting only the long end of the yield curve. For instance, Smets and Tsatsaronis (1997) interpret it as an "inflation scare" shock.

Let

$$
\varepsilon_{t}=\left(\begin{array}{c}
\varepsilon_{t}^{s} \\
\varepsilon_{t}^{d} \\
\varepsilon_{t}^{p} \\
\varepsilon_{t}^{l r}
\end{array}\right)
$$

be the vector of structural disturbances. The statistical innovations vector $U_{t}$ can be written as a linear combination of structural innovations :

$$
U_{t}=D \varepsilon_{t}
$$

In order to identify the matrix $D$, we must impose $\frac{(4 \times 3)}{2}=6$ restrictions. The restrictions we use call for a mixture of short and long-run zero restrictions as in Smets and Tsatsaronis (1997), Gali (1992) and Blanchard and Quah (1989).

\section{R1, R2, R3 : supply shocks identification}

Demand and nominal shocks have no long-run impact on the level of real output. This is the analogue of the assumption of a vertical long-run Phillips curve.

\section{R4, R5 : demand shocks identification}

Demand shocks are distinguished from nominal shocks by the assumption that the latter do not contemporaneously affect real output. Assuming that there are lags in the monetary transmission mechanism to output is not very controversial and has been used extensively in the VAR literature to identify monetary policy shocks ${ }^{7}$.

\section{R6 : monetary policy shocks identification}

Finally we need one additional assumption to distinguish monetary policy

\footnotetext{
${ }^{7}$ See, for example, Bernanke and Blinder (1989), Gali (1992) and Christiano, Eichembaum and Evans (1991).
} 
shocks from long term rate shocks. For this purpose, we assume that the "long term interest rate" shock does not affect contemporaneously the short rate. In others words, the only interest rate shock that contemporaneously affect the short rate is the monetary policy one.

\subsection{Predictive power decomposition}

One interesting property of the S-VAR representation is its ability to express all the variables in terms of present and past structural disturbances. This is provided by the Structural Vectorial Moving Average representation (thereafter S-VMA). Using this representation, we construct two indicators that enable us to evaluate the capacity of each structural shock to generate the LIPTS.

The first one follows from the work of Smets and Tsatsaronis (1997). They calculate the percentage contribution of each shock in the total covariance between spread and future activity ${ }^{8}$. In fact, this approach equivalently provides a decomposition of the theoretical $R^{2}$ of regression (2). To see this, consider the structural moving average representation of the interest rates spread :

$$
R_{t}-i_{t}=\sum_{\tau=\{s, d, p, l r\}} C_{\tau}(L) \varepsilon_{t}^{\tau}
$$

where $C_{\tau}(L)$ are four polynomial functions of the lag operator.

We note $R_{t}(\tau)-i_{t}(\tau)=C_{\tau}(L) \varepsilon_{t}^{\tau}$, the part of the interest rates spread at date $t$ generated by past and present values of the shock $\tau$, and $\widetilde{\Delta} y_{t}=E_{t}\left(y_{t}-y_{t-12}\right)$. Then, for a given forecast horizon $k$, we decompose the theoretical $R^{2}$ of (2) into:

$$
R^{2}=\frac{\operatorname{cov}\left(R_{t-k}-i_{t-k}, \widetilde{\Delta} y_{t}\right)^{2}}{\operatorname{var}\left(R_{t-k}-i_{t-k}\right) \operatorname{var}\left(\widetilde{\Delta} y_{t}\right)}=\sum_{\tau=\{s, d, p, l r\}} R^{2}(\tau)
$$

\footnotetext{
${ }^{8}$ See the appendix for details.
} 
where

$$
R^{2}(\tau)=\operatorname{cov}\left(R_{t-k}(\tau)-i_{t-k}(\tau), \widetilde{\Delta} y_{t}\right) \frac{\operatorname{cov}\left(R_{t-k}-i_{t-k}, \widetilde{\Delta} y_{t}\right)}{\operatorname{var}\left(R_{t-k}-i_{t-k}\right) \operatorname{var}\left(\widetilde{\Delta} y_{t}\right)}
$$

The first indicator we consider is :

$$
\frac{R^{2}(\tau)}{R^{2}}=\frac{\operatorname{cov}\left(R_{t-k}(\tau)-i_{t-k}(\tau), \widetilde{\Delta} y_{t}\right)}{\operatorname{cov}\left(R_{t-k}-i_{t-k}, \widetilde{\Delta} y_{t}\right)}
$$

This expression measures the percentage contribution of each shock to the total $R^{2}$, or equivalently, the percentage of total covariance generated by the shock $\tau$.

We compute expression (9) for each structural shock using estimation of the S-VMA representation on the first and the second sub-sample. The results are given in Table 11 .

$$
\text { (insert here Table 11) }
$$

The second indicator evaluates, for each structural shock, the percentage of future activity explained by the part of the spread generated by this shocks ${ }^{9}$. In other words, for a given $k$ we consider the regressions:

$$
\widetilde{\Delta} y_{t}=\alpha+\beta\left(R_{t-k}(\tau)-i_{t-k}(\tau)\right)+\eta_{t}
$$

for $\tau=\{s, d, p, l r\}$

The coefficient of determination of this regression is given by (11). To differentiate it from the previous one, we note it $r^{2}(\tau)$ for $\tau=\{s, d, p, l r\}$ :

$$
r^{2}(\tau)=\frac{\operatorname{cov}\left(R_{t-k}(\tau)-i_{t-k}(\tau), \widetilde{\Delta} y_{t}\right)^{2}}{\operatorname{var}\left(R_{t-k}(\tau)-i_{t-k}(\tau)\right) \operatorname{var}\left(\widetilde{\Delta} y_{t}\right)}
$$

\footnotetext{
${ }^{9}$ In this sense, our approach is close to, but different from the one proposed by Peel and Taylor (1998) who operate a Blanchard-Quah (1989) decomposition of GDP series and explore the respective predictive power of a ten-year spread for each of these components. Looking at both US and UK data, they find that prediction from the spread bears only on the demand driven component (i.e output component purged from supply innovations).
} 
Once again, this expression is computed from the S-VMA representation estimated, for each structural shock, before and after the 1984 structural change. The results are reported in Table 12.

$$
\text { (insert here Table 12) }
$$

In accordance with the results of Tables 2 and 3 , the $R^{2}$ decreases in the second sub-sample for all forecast horizons. This decline reveals a weakening of the LIPTS.

The most striking result in Table 11, is the decrease in the contribution of the monetary policy shock in the total covariance between the spread and real activity. Before 1984, 48\% of the total covariance between the spread and the growth rate of real GDP one year ahead is provided by the monetary policy shock. After this date, the higher contribution recorded by this same shock is only $25 \%$ of the total covariance. The relative contributions of the other shocks correspondingly increase on average.

As judged from the Table 12, the results in terms of percentage of activity explained by spread generated by one shock are slightly different. Indeed, we notice a drop in the $r^{2}(\tau)$ obtained for "supply" shocks, and "monetary policy" shocks. Before 1984, the interest rates spread due to monetary policy shocks helps to predict $39 \%$ of the growth rate of GDP one year ahead. After 1984 , the part of the spread generated by monetary policy shocks seems to provide no information concerning future real activity. The same result is obtained with the part of the spread generated by supply shocks. Contribution of the "long term" shock slightly decreases, whereas the impact of the demand shock remains more or less constant after the break.

The loss of the predictive power of the term structure can be in part explained by the declining role of monetary policy shocks. This conclusion is not surprising. The LIPTS is often explained by the negative correlation between the short term interest rate and future activity. However, recent 
VAR studies ${ }^{10}$ have noted the falling impact of monetary policy shocks on activity since 1980 : exogenous change of federal fund rates have less influence on activity and inflation. Every factor that weakens the effects of the short rate on activity may be responsible for the loss of predictive power of the spread. The fact that the breakpoint is identified in 1984 indicates that one potential factor is financial innovation.

\section{Conclusion}

In this paper, we have carried out an empirical investigation of the observed correlation between the slope of the yield curve and movements in real activity.

In a first approximation, we applied a test proposed by Bai and Perron (1998) and we detected a break in this empirical relationship in 1984. We then showed that this break is associated with the loss of the predictive power of the term structure.

Hence, in a second part, we identify reasons of this change. We estimated a structural VAR-VECM model. We used a standard mixture of short term and long term restrictions to identify four structural disturbances : a supply, a demand, a monetary policy and a long term interest rate shocks. Thus, we were able to calculate two indicators that measure the role of each structural shock in generating the LIPTS. The results strongly support that the loss of predictive power of the term structure is due to a substantial drop in the contribution of monetary policy shocks on one hand, and in the contribution of supply shocks on the other hand, in reproducing the LIPTS.

\footnotetext{
${ }^{10}$ See Bernanke and Mihov (1998), Gertler and Lown (2000).
} 


\section{References}

[1] Andrews D.W.K., 1993, Test for parameter instability and structural change with unknown change point, Econometrica $61,821-856$.

[2] Andrews D.W.K. and Fair R., 1988, Inference in econometric models with structural change, Review of Economic Studies 55, 615-640.

[3] Andrews D.W.K. and Ploberger W., 1994, Optimal tests when a nuisance parameter is present only under the alternative, Econometrica 62, 1383-1414.

[4] Andrews D.W.K. and Ploberger W., 1995, Admissibility of the likelihood ratio test when a nuisance parameter is present only under the alternative, Annals of Statistics 23, 1606-1629.

[5] Bai J. and P. Perron, 1998, Estimating and Testing linear models with multiple structural changes, Econometrica, 66, 47-78.

[6] Bernanke B.S. and A.S. Blinder, 1992, The Federal Fund Rate and the channels of monetary transmission, American Economic Review 82, 901921.

[7] Bernanke B.S. and I. Mihov, 1998, Measuring monetary policy, Quaterly Journal of Economics 113(3), 869-902.

[8] Boivin J. and M. Giannoni, 2001, The monetary Transmission Mechanism : Has it changed ?, Discussion Paper, Federal Reserve Bank of New-York.

[9] Chen N.F., 1991, Financial investment opportunities and the macroeconomy, Journal of Finance 46, 529-554.

[10] Chow G.C. and A.L. Lin, 1976, Best linear unbiased estimation of missing observation in an economic time series, Journal of the American Statistical Association 71, 719-721. 
[11] DeLong D.M., 1981, Crossing probabilities for square root boundary by a Bessel process, Communication in Statistics-Theory and Methods, A10(21), 2197-2213.

[12] Engle R. and C. Granger, 1987, Cointegration and error correction representation, estimation and testing, Econometrica 55, 251-276.

[13] Estrella A., 1997, Why does interest rate predict macro outcomes ? A unified theory of inflation, output, interest and policy, Federal Reserve Bank of New-York Research Paper 9717.

[14] Estrella A. and G. Hardouvelis, 1991, The term structure as a predictor of real economic activity, Journal of Finance 46, 555-576.

[15] Estrella A. and F. Mishkin, 1997, The predictive power of the term structure of interest rates in Europe and in the United States : implications for the European Central Bank, European Economic Review 41(7), 555-576.

[16] Estrella A. A.P. Rodrigues and S. Schich, 2000, How stable is the predictive power of the yield curve? Evidence from Germany and the United State, Discussion Paper, Federal Reserve Bank of New-York.

[17] Fuhrer J.C. and G.R. Moore, 1995, Monetary policy trade-offs and the correlation between nominal interest rates and real output, American Economic Review 85(1), 219-239.

[18] Gali J., 1992, How well does the IS-LM fit the US post war data? Quarterly Journal of Economics 107, 709-738.

[19] Gertler M. et S. lown, The Information in the High Yield Bond Spread for the Business Cycle: Evidence and Some Implications 2000, NBER Working Paper 7549.

[20] Goodfriend M., 1993, Interest Rate Policy and the Inflation Scare Problem : 1979-1992, Economic Quaterly, Federal Reserve of Richmond, $79(1)$. 
[21] Harvey C.R., 1988, The real term structure and consumption growth, Journal of Financial Economics 22, 305-333.

[22] Harvey C.R., 1989, Forecasts of economic growth from the bond and stock markets, Financial Analysts Journal 45(5), 38-45.

[23] Hu Z., 1993, The yield curve and real activity, International Monetary Fund staff Papers vol. 40(4), 781-806.

[24] Johansen S., 1988, Statistical Analysis of cointegration vectors, Journal of Economics Dynamics and Control, 231-254.

[25] Johansen S. 1991, Estimation and hypothesis testing of cointegration vectors in gausian vector autoregressive models, Econometrica 59.

[26] Johansen S. and Juselius K., 1990, Maximum Likelihood estimation and inference on cointegration, with applications to the demand for money, Oxford Bulletin of Economics and Statistics 52, 169-210.

[27] Johansen S. and Juselius K., 1991, Testing structural hypothesis in a multivariate cointegration analysis of the PPP and UIP for UK, Journal of Econometrics.

[28] Newey W.K. and K.D. West, 1987, A simple positive definite heteroskedasticity and autocorreelation consistent covariance matrix, Econometrica 29, 305-325.

[29] Newey W.K. and K.D. West, 1994, automatic lag selection in covariance estimation, Review of Economic Studies 61, 631-653.

[30] Peel D.A. and M.P. Taylor, 1998, The slope of the yield curve and real economic activity: tracing the transmission mechanism, Economic Letters. 59, 353-360.

[31] Plosser C.I. and K.G. Rouwenhorst, 1994, International term structure and real economic growth, Journal of Monetary Economics 33, 133-156.

[32] Smets F. and K. Tsatsaronis, 1997, Why does the yield curve predict economic activity? dissecting the evidence for Germany and the United Sates, BIS Working Paper. 
[33] Sowel F., 1996a, Optimal tests for parameter instability in the generalized method of moments framework, Econometrica 64, 1085-1108.

[34] Sowel F., 1996b, Test for violation of moment conditions, Dicussion Paper, Graduate School of Administration, Carnegie Mellon University, Pittsburgh, PA.

[35] Stock J.H. and M.H. Watson, 1989, New indexes of coincident and leading economic indicators, dans O.J. Blanchard et S. Fisher (eds. ), NBER Macroeconomic annual 1989, 352-394.

[36] Svensson L.E.O., 1997, Inflation forecast targeting : implementing and monitoring inflation targets, European Economic Review 41(6), 11111146. 


\section{The data}

- Output : $y_{t}$

According to the Chow and Lin (1976) methodology, we construct a monthly database for US Gross Domestic Product ( GDPQ, CITIBASE, seasonally adjusted ). Monthly data we used are :

- a Production Index ( INDPRO, Federal reserve Board of Governors database, seasonally adjusted ).

- an employment rate ( Non Farm Employment, Bureau of Labor Statistic, seasonally adjusted ).

Then, the "monthly" (logged) GDP is detrended, using its average growth rate as an estimate of the rate of drift.

- Prices : $p_{t}$

To measure price level we use the "CPI less food and energy", seasonally adjusted, given by BLS database. The (logged) data are then detrended, using its average growth of rate as an estimate of the rate of drift.

- Interest rate : $i_{t}$ and $R_{t}$

Interest rate data comes from the Federal Reserve of Governors database.

- short rate $i_{t}$ : Federal Fund Rate.

- long rate $R_{t}$ : 10 years Constant Maturity Rate (GS10). 


\begin{tabular}{|c|c|c|c|}
\hline data & ADF t-statistique & mean & std \\
\hline$y_{t}$ & -1.41 & 737 & 5.05 \\
\hline$p_{t}$ & -1.01 & 331 & 14.7 \\
\hline$i_{t}$ & -2.35 & 6.35 & 3.33 \\
\hline$R_{t}$ & -1.78 & 7.14 & 2.64 \\
\hline$R_{t}-i_{t}$ & $-3.55^{* * *}$ & 0.78 & 1.68 \\
\hline$\pi$ & $-3.13^{* *}$ & 0.01 & 0.27 \\
\hline$i_{t}-\pi_{t}$ & -2.35 & 6.35 & 3.17 \\
\hline$R_{t}-\pi_{t}$ & -1.74 & 7.14 & 2.51 \\
\hline
\end{tabular}

${ }^{* *} 5 \%$ rejection of unit root hypothesis, ${ }^{* * *} 1 \%$ rejection of unit root hypothesis 


\section{Test for multiple structural changes}

Bai and Perron (1998) propose a sequential procedure that makes it possible to test for more than one structural change in the linear regression model. The dates of the breaks are treated as unknown variables to be estimated. The method of estimation considered is based on the least-squares. To facilitate the presentation we consider the following multiple linear regression with $m$ breaks :

$$
y_{t}=x_{t}^{\prime} \beta+z_{t}^{\prime} \delta_{j}+u_{t} \quad\left(t=T_{j-1}+1, \ldots, T_{j}\right)
$$

for $j=1, \ldots, m+1$ and where we use the convention that $T_{0}=0$ and $T_{m+1}=T$.

In this model, $y_{t}$ is the observed independent variable, $x_{t}$ the $(p \times 1)$ and $z_{t}$ the $(q \times 1)$ vectors of covariates, and $\beta$ and $\delta_{j}(j=1, \ldots, m+1)$ are the corresponding vectors of coefficients. $\mathrm{T}$ observations of $\left(y_{t}, x_{t}, z_{t}\right)$ are available.

The method of estimation is based on least-squares. For each $m$-partition $\left(T_{1}, \ldots, T_{m}\right)$, the associated least squares estimates of $\beta$ and $\delta_{j}$ are obtained by minimizing the sum of square residuals $S_{T}\left(T_{1}, \ldots, T_{m}\right)=\sum_{i=1}^{m+1} \sum_{t=T_{i-1}+1}^{T_{i}}\left[y_{t}-\right.$ $\left.x_{t}^{\prime} \beta-z_{t}^{\prime} \delta_{i}\right]^{2}:$

$$
\left(\widehat{T}_{1}, \ldots, \widehat{T}_{m}\right)=\operatorname{argmin}_{T_{1}, \ldots, T_{m}} S_{T}\left(T_{1}, \ldots, T_{m}\right)
$$

Then, it is possible to test the null hypothesis of $l$ breaks against the alternative that an additional break exists. The procedure proposed by Bai and Perron is the following. For the model with $l$ breaks, the estimated break

points, denoted $\widehat{T}_{1}, \ldots, \widehat{T}_{l}$, are obtained by a global minimization of the sum of square residuals. Their strategy proceeds by testing each $(l+1)$ segment for the presence of an additional break. They conclude for rejection in favor of a model with $(l+1)$ breaks if the overall minimal value of the sum of squared residuals (over all segments where an additional break is included) is sufficiently smaller than the sum of squared residuals from the $l$ break model. The breakpoint thus selected is the one associated with the overall 
minimum. More precisely the test is defined by :

$F_{T}(l+1 \mid l)=\left\{S_{T}\left(\widehat{T}_{1}, \ldots, \widehat{T}_{l}\right)-\min _{1 \leq i \leq l+1} \quad i n f_{\tau \in \Delta_{i, \tau}} S_{T}\left(\widehat{T}_{1}, \ldots, \widehat{T}_{i-1}, \tau, \widehat{T}_{i}, \ldots, \widehat{T}_{l}\right)\right\} / \widehat{\sigma}^{2}$

where

$$
\Delta_{i, \tau}=\left\{\tau ; \widehat{T}_{i-1}-\left(\widehat{T}_{i}-\widehat{T}_{i-1}\right) \tau \leq \tau \leq \widehat{T}_{i}-\left(\widehat{T}_{i}-\widehat{T}_{i-1}\right) \tau\right\}
$$

and $\widehat{\sigma}^{2}$ is a consistent estimate of $\sigma^{2}=\operatorname{var}\left(u_{t}\right)$ under the null hypothesis.

Thus, under a set of assumptions ${ }^{11}$, and $m=l$, we have the following result:

$\lim _{T \rightarrow \infty} P\left(F_{T}(l+1 \mid l) \leq x\right)=G_{q, \tau}(x)^{l+1}$ with $G_{q, \tau}(x)^{l+1}$ the distribution function of $\sup _{\tau \leq \mu \leq 1-\tau}\left\|W_{q}(\mu)-\mu W_{q}(1)\right\|^{2}(\mu(1-\mu))$.

The critical values of this test for different values of $l$ can be obtained from the distribution function $G_{q, \tau}(x)$. A partial tabulation of some quantiles points can be found in DeLong (1981), Andrews (1993) (first column of table I), and Bai and Perron (1998) for $\tau=0.05$.

\footnotetext{
${ }^{11}$ See Bai and Perron (1998)
} 


\begin{tabular}{clcc}
\hline horizon & $\beta$ & t-stat & $R^{2}$ \\
\hline 0 & 0.05 & 0.42 & 0.00 \\
6 & $0.50^{* * *}$ & 3.84 & 0.12 \\
12 & $0.77^{* * *}$ & 5.34 & 0.30 \\
18 & $0.57^{* * *}$ & 4.26 & 0.16 \\
24 & $0.24^{*}$ & 1.77 & 0.02 \\
30 & -0.01 & 0.09 & 0.00 \\
\hline
\end{tabular}

Table 1: Estimation on the whole sample

\begin{tabular}{clcc}
\hline horizon & $\beta$ & t-stat & $R^{2}$ \\
\hline 0 & 0.11 & 0.68 & 0.00 \\
6 & $0.74^{* * *}$ & 5.15 & 0.23 \\
12 & $1.12^{* * *}$ & 10.27 & 0.52 \\
18 & $0.81^{* * *}$ & 4.79 & 0.27 \\
24 & $0.34^{* *}$ & 2.02 & 0.04 \\
30 & -0.00 & 0.01 & 0.00 \\
\hline
\end{tabular}

Table 2: Estimation on the first sub-sample 


\begin{tabular}{clcc}
\hline horizon & $\beta$ & t-stat & $R^{2}$ \\
\hline 0 & -0.14 & 1.00 & 0.01 \\
6 & 0.12 & 0.89 & 0.01 \\
12 & 0.31 & 1.31 & 0.07 \\
18 & $0.40^{* *}$ & 2.55 & 0.11 \\
24 & 0.45 & 1.43 & 0.14 \\
30 & $0.36^{*}$ & 1.79 & 0.09 \\
\hline
\end{tabular}

Table 3: Estimation on the second sub-sample

\begin{tabular}{ccc}
\hline$l$ against $l+1$ breaks & $F_{T}(l+1 \mid l)$ statistic & date \\
\hline horizon $=6$ & & \\
$l=0$ & $54.45^{* * *}$ & $1984-04$ \\
$l=1$ & 3.69 & $1990-03$ \\
\hline horizon $=12$ & & \\
$l=0$ & $85.29^{* * *}$ & $1984-02$ \\
$l=1$ & 6.69 & $1970-05$ \\
\hline horizon $=18$ & & \\
$l=0$ & $53.68^{* * *}$ & $1983-12$ \\
$l=1$ & 5.76 & $1974-06$ \\
\hline horizon $=24$ & & \\
$l=0$ & $11.01^{* *}$ & $1983-12$ \\
$l=1$ & 3.44 & $1971-02$ \\
\hline horizon $=30$ & & \\
$l=0$ & 5.43 & $1980-07$ \\
$l=1$ & 3.31 & $1971-03$ \\
\hline
\end{tabular}

${ }^{*} 10 \%$ rejection of the null hypothesis, ${ }^{* *} 5 \%$ rejection of the null hypothesis, ${ }^{* * *}$ $1 \%$ rejection of the null hypothesis

Table 4: Sequential test for multiple breaks between 1970-01 and 1995-05 


\begin{tabular}{cc}
\hline number of lags & AIC \\
\hline 2 & -6.96 \\
4 & -7.00 \\
5 & -7.08 \\
6 & -6.95 \\
8 & -6.91 \\
10 & -6.75 \\
\hline
\end{tabular}

Table 5: AIC - first sub-sample

\begin{tabular}{lcc}
\hline & Trace Statistic & $95 \%$ critical value \\
\hline$r=0$ & 75.83 & 47.85 \\
$r \leq 1$ & 38.76 & 29.79 \\
$r \leq 2$ & 13.14 & 15.49 \\
$r \leq 3$ & 0.10 & 3.84 \\
\hline
\end{tabular}

Table 6: Trace statistic - first sub-sample

\begin{tabular}{lcc}
\hline & Eigenvalue Statistic & $95 \%$ critical value \\
\hline$r=0$ & 37.07 & 27.58 \\
$r \leq 1$ & 25.61 & 21.13 \\
$r \leq 2$ & 13.04 & 14.26 \\
$r \leq 3$ & 0.10 & 3.84 \\
\hline
\end{tabular}

Table 7: $\lambda_{\max }$ statistic - first sub-sample 


\begin{tabular}{cc}
\hline number of lags & AIC \\
\hline 2 & -12.45 \\
4 & -12.51 \\
6 & -12.53 \\
7 & $\mathbf{- 1 2 . 6 7}$ \\
8 & -12.61 \\
10 & -12.59 \\
\hline
\end{tabular}

Table 8: AIC - second sub-sample

\begin{tabular}{lcc}
\hline & Trace Statistic & $95 \%$ critical value \\
\hline$r=0$ & 66.86 & 47.85 \\
$r \leq 1$ & 30.50 & 29.79 \\
$r \leq 2$ & 10.47 & 15.49 \\
$r \leq 3$ & 0.01 & 3.84 \\
\hline
\end{tabular}

Table 9: Trace statistic - second sub-sample

\begin{tabular}{lcc}
\hline & Eigenvalue Statistic & $95 \%$ critical value \\
\hline$r=0$ & 36.35 & 27.58 \\
$r \leq 1$ & 21.21 & 21.13 \\
$r \leq 2$ & 10.46 & 14.26 \\
$r \leq 3$ & 0.01 & 3.84 \\
\hline
\end{tabular}

Table 10: $\lambda_{\max }$ statistic - second sub-sample 


\begin{tabular}{|c|c|c|c|c|c|}
\hline \multicolumn{6}{|c|}{ first sub-sample } \\
\hline \multicolumn{6}{|c|}{ shocks } \\
\hline horizon & supply & demand & monetary policy & long rate & total $R^{2}$ \\
\hline 6 & 0.38 & 0.05 & 0.51 & 0.06 & 0.80 \\
\hline 12 & 0.39 & 0.06 & 0.48 & 0.08 & 0.90 \\
\hline 18 & 0.41 & 0.07 & 0.43 & 0.09 & 0.77 \\
\hline 24 & 0.48 & 0.11 & 0.33 & 0.09 & 0.51 \\
\hline 30 & 0.63 & 0.16 & 0.15 & 0.06 & 0.25 \\
\hline \multicolumn{6}{|c|}{ second sub-sample } \\
\hline \multicolumn{6}{|c|}{ shocks } \\
\hline horizon & supply & demand & monetary policy & long rate & total $R^{2}$ \\
\hline 6 & 0.49 & 0.48 & -0.27 & 0.30 & 0.02 \\
\hline 12 & 0.51 & 0.51 & -0.26 & 0.24 & 0.03 \\
\hline 18 & 0.32 & 0.39 & 0.10 & 0.20 & 0.08 \\
\hline 24 & 0.27 & 0.32 & 0.22 & 0.19 & 0.13 \\
\hline 30 & 0.25 & 0.31 & 0.25 & 0.19 & 0.12 \\
\hline
\end{tabular}

Table 11: $\frac{R^{2}(\tau)}{R^{2}}$ decomposition 


\begin{tabular}{|c|c|c|c|c|c|}
\hline \multicolumn{6}{|c|}{ first sub-sample } \\
\hline \multicolumn{6}{|c|}{ shocks } \\
\hline horizon & supply & demand & monetary policy & long rate & total $R^{2}$ \\
\hline 6 & 0.39 & 0.05 & 0.41 & 0.06 & 0.80 \\
\hline 12 & 0.39 & 0.07 & 0.39 & 0.07 & 0.90 \\
\hline 18 & 0.37 & 0.10 & 0.27 & 0.08 & 0.77 \\
\hline 24 & 0.33 & 0.13 & 0.10 & 0.05 & 0.51 \\
\hline 30 & 0.29 & 0.15 & 0.01 & 0.01 & 0.25 \\
\hline \multicolumn{6}{|c|}{ second-subsample } \\
\hline \multicolumn{6}{|c|}{ shocks } \\
\hline horizon & supply & demand & monetary policy & long rate & total $R^{2}$ \\
\hline 6 & 0.04 & 0.06 & 0 & 0.01 & 0.02 \\
\hline 12 & 0.05 & 0.05 & 0 & 0.01 & 0.03 \\
\hline 18 & 0.06 & 0.09 & 0 & 0.03 & 0.08 \\
\hline 24 & 0.07 & 0.10 & 0.01 & 0.04 & 0.13 \\
\hline 30 & 0.06 & 0.09 & 0 & 0.04 & 0.12 \\
\hline
\end{tabular}

Table 12: $r(\tau)^{2}$ decomposition 


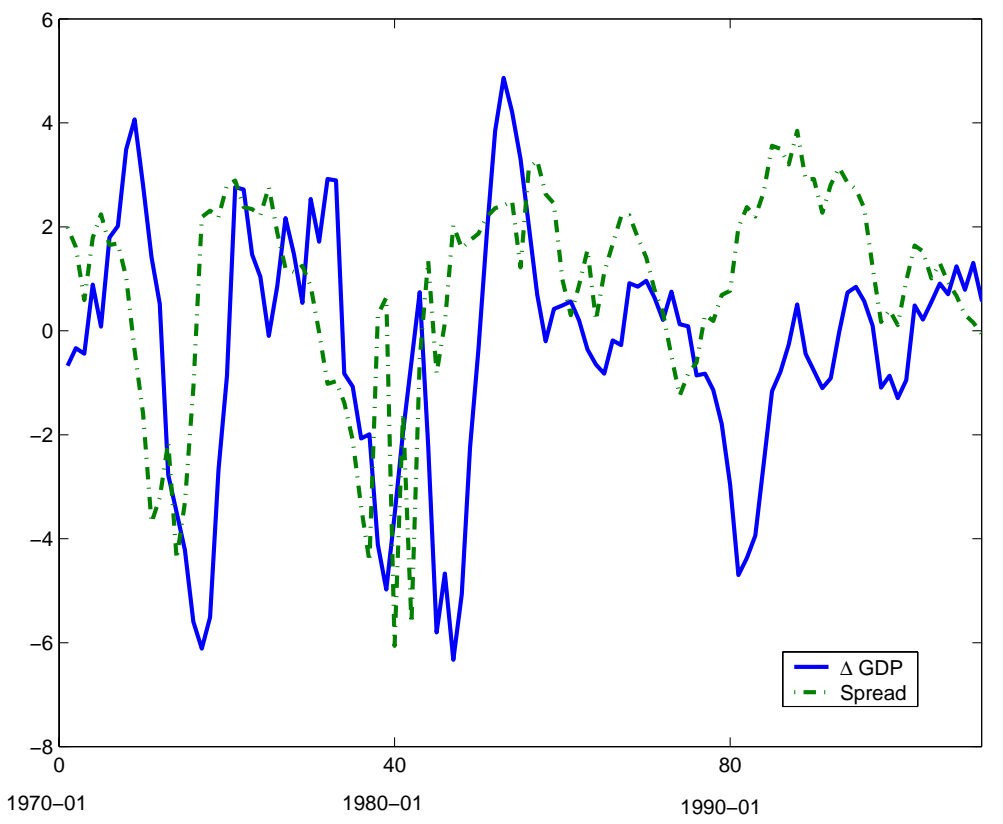

Figure 1: The predictive power of the term structure 